subunit assay), pregnancy-specific $\beta_{1}$-glycoprotein, and $\alpha$ fetoprotein persist longer after some spontaneous abortions than after the birth of normal babies. Pastorfide et $a l^{19}$ showed that HCG persists for about twice as long after therapeutic abortions as after normal vaginal delivery (22 days as opposed to 11 ) and attributed this to viable trophoblastic cells being left in the uterus after surgical intervention, since after term delivery there is a more complete removal of placental tissue.

Whatever the correct explanation our findings suggest that spontaneous abortions are more relevant to ASB and other abnormalities than has been thought. Because of the short IPG in many of the index cases it might be informative to determine whether the incidence of malformations is reduced when a subsequent pregnancy is delayed after a spontaneous abortion, especially if the HCG concentration is raised. There has been a pronounced fall in the birth rate, particularly in social classes IV and V, which is probably the result of family-planning campaigns. Additional advice could easily be given about procedure after a spontaneous abortion, and if this were done and our hypothesis is correct the incidence of ASB and probably other abnormalities would automatically fall.

We thank the obstetricians and paediatricians at Broadgreen, Fazakerly, the Maternity, Mill Road, and Sefton General hospitals, Liverpool, for allowing us to study their case notes, and the clerical staff in the records offices of these hospitals for much help. We are indebted to Professor Frank Harris for valuable advice, and Dr S C Rogers for useful discussions. We are grateful to the F B Baily Charitable Trust and the Nuffield Foundation for financial support.

Requests for reprints should be addressed to: Sir Cyril Clarke,
Nuffield Unit of Medical Genetics, University of Liverpool, Liverpool L69 3BX.

\section{References}

${ }^{1}$ Knox, E G, Developmental Medicine and Child Neurology, 1970, 12, 167.

2 Clarke, C A, et al, British Medical fournal, 1975, 4, 743.

${ }^{3}$ Field, Barbara, and Kerr, C, British Medical fournal, 1976, 3, 107.

4 Laurence, K M, and Roberts, C J, British Medical fournal, 1977, 3, 361.

${ }^{5}$ James, W H, British Medical fournal, 1978, 1, 72.

${ }^{6}$ Smithells, R W, British fournal of Preventive and Social Medicine, 1968, 으 22, 36.

'Fedrick, Jean, and Adelstein, Philippa, British Medical fournal, 1973, 4, 753.

${ }^{8}$ Till, K, Developmental Medicine and Child Neurology, 1968, 10, 471.

9 Carter, C O, Evans, K A, and Till, K, fournal of Medical Genetics, 1976, $13,343$.

10 Vulliamy, D G, The Newborn Child, 4th edn. Edinburgh, Churchill $\vec{\circ}$ Livingstone, 1977.

11 Creasy, M R, and Alberman, Eva D, fournal of Medical Genetics, 1976, $\vec{\omega}$ 13, 9.

12 Rushton, D I, fournal of Medical Genetics, 1978, 15, 1.

${ }_{13}$ Daling, Janet R, and Emanuel, I, New England fournal of Medicine, 1977, 297, 1241.

${ }_{14}$ Pantelakis, S N, Papadimitriou, G, and Doxiadis, S A, American fournal of Obstetrics and Gynecology, 1973, 116, 799.

15 Fedrick, Jean, and Adelstein, Philippa, Biology of the Neonate, 1977, 31, 84

16 Stevenson, A C, and McClarin, R H, Nature, 1957, 180, 198.

17 Clarke, C A, et al, British Medical fournal, 1976, 1, 455.

18 Roberts, C J, and Powell, R G, Lancet, 1975, 2, 848.

19 Pastorfide, Greg B, et al, American fournal of Obstetrics and Gynecology, 1974, 118, 293.

(Accepted 8 February 1978)

\title{
Creamatocrit: simple clinical technique for estimating fat concentration and energy value of human milk
}

\author{
A LUCAS, J A H GIBBS, R L J LYSTER, J D BAUM
}

British Medical fournal, 1978, 1, 1018-1020

\section{Summary and conclusions}

A simple micromethod has been devised for estimating the fat and energy content of human milk based on the centrifugation of milk in a haematocrit centrifuge. The percentage of cream, or "creamatocrit," is read from the haematocrit capillary tube and is linearly related to the fat and energy content.

The technique, which is rapid and cheap, may be used in clinical practice, in research, and in epidemiological studies.

\footnotetext{
University Department of Paediatrics, John Radcliffe Hospital, Oxford OX3 9DU

A LUCAS, MB, MRCP, research fellow

J A H GIBBS, MD, medical research fellow (now at Royal Victoria Hospital, Neonatal Unit, Women's Pavilion, Montreal, Canada)

J D BAUM, MD, FRCP, clinical reader

National Institute for Research in Dairying, Oxford

R L J LYSTER, MA, PHD, principal scientific officer
}

\section{Introduction}

There has been increasing interest in human milk in the $ᄋ$ community, in special-care baby units, and in the Third World. Many of the methods for studying the composition of human 을 milk, however, are lengthy, require technical skill, and often N entail using special equipment or reagents. Such studies are therefore not practicable for many potential investigators.

An important variable in studies of breast milk is the fat concentration, which is the major determinant of the energy value. There is a need for a quick and simple micromethod for $\omega$ estimating milk fat and energy that may be used in the nursery, in the research laboratory, or in the field. Fleet and Linzell ${ }^{10}$ described a method for estimating fat in goats' milk on very small samples by the microcentrifugation of milk in glass capillary ${ }^{+}$ tubes. Their preliminary data on other species suggested that this $\frac{0}{0}$ technique might be developed for use in man.

\section{Materials and methods}

For the present technique we used a haematocrit centrifuge (Hawksley, London), standard glass capillary tubes $(75 \times 1.5 \mathrm{~mm}$ outside diameter), and vernier callipers. From well-mixed samples of fresh untreated human milk approximately $75 \mu \mathrm{l}$ was drawn by capillarity into the standard glass capillary tubes. These were then sealed at one end by means of a flame and centrifuged for 15 minutes at $12000 \mathrm{~g}$. To prevent the cream layer "setting" at an angle the 
tubes were removed immediately the centrifuge had stopped and placed vertically-for example, in Plasticine-with the cream layer uppermost. The cream layer (fig 1) was read with the vernier callipers to the nearest $0.05 \mathrm{~mm}$ and expressed as a percentage of the length of the milk column in the tube-that is, the "creamatocrit." In place of vernier callipers a microscope incorporating a moving stage with a vernier scale may be used. Since the cream layer is opaque it was measured to the top rather than the bottom of the meniscus. When a layer of liquid fat was present at the top of the cream layer it was included with the cream.

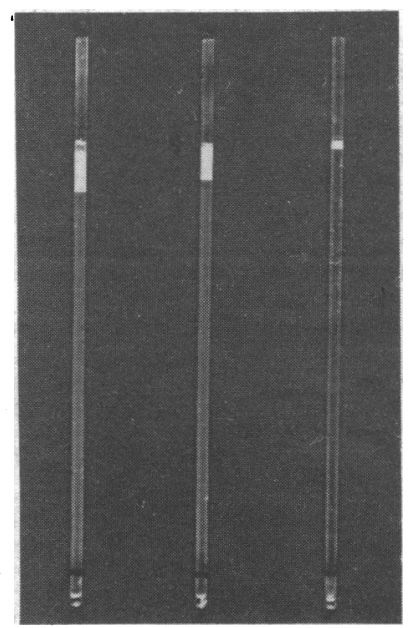

FIG 1 -The creamatocrit. Three centrifuged milk samples with different cream contents. From left to right, creamatocrits are $11 \%, 8 \%$, and $2 \%$. Left-hand tube shows free fat layer above cream.

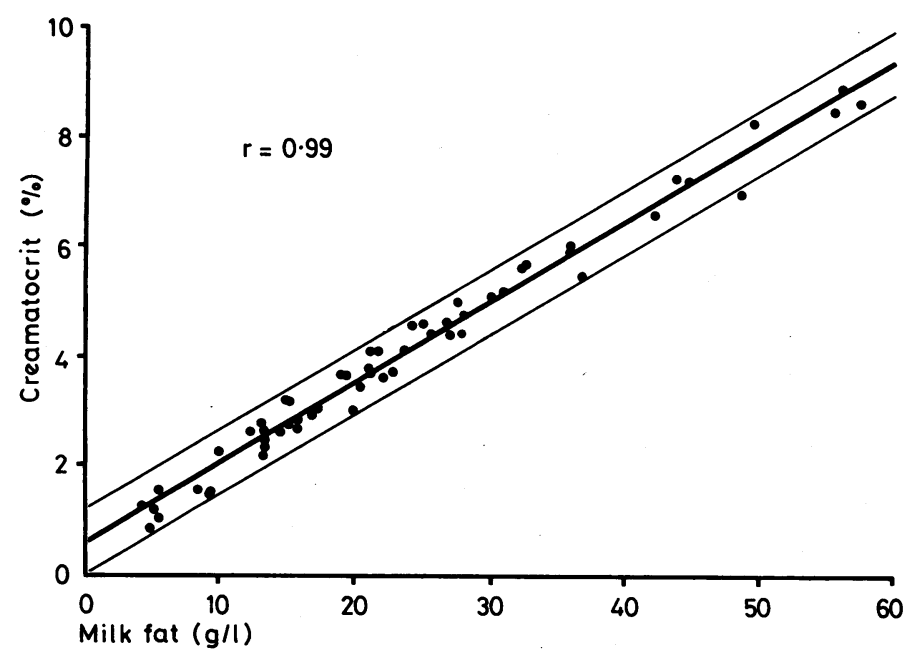

FIG 2-Relation between creamatocrit and milk fat concentration determined by Gerber method. ${ }^{2}$ Linear regression line with $95 \%$ confidence limits.

Sixty samples of human milk were analysed, comprising 23 expressed breast-milk samples and 37 samples of milk that had dripped from the opposite breast during breast-feeding. The creamatocrit was measured in triplicate within 30 minutes of centrifugation (beyond one hour after centrifugation the cream column begins to "unpack" and slightly higher readings are obtained).

The fat concentration of the milk samples was also measured by the Gerber method (British Standard). ${ }^{2}$ Total protein was measured by the biuret method described by Bosset $e t$ al. ${ }^{3}{ }^{4}$ Lactose was measured by the phenol-sulphuric acid colorimetric method of Marier and Boulet. $^{5}$

\section{Results}

Figure 2 shows the linear relation between the fat concentration measured by the Gerber method and the creamatocrit. The regression line $(r=0.99)$ intersects the ordinate rather than passing through the origin because reading the cream layer to the top of the meniscus produces a small overestimate of creamatocrit. The accuracy of the method ( $95 \%$ confidence limits) is $\pm 4.2 \mathrm{~g}$ of fat $/ \mathrm{l}$, which for expressed milk of average composition is around $10 \%$. (The accuracy of the Gerber method is $\pm 0.05 \%$ of fat.)

Figure 3 shows the linear relation between the calculated energy value $(\mathrm{kcal} / \mathrm{l})$ and the creamatocrit $(r=0.99)(1000 \mathrm{kcal} \approx 4.2 \mathrm{MJ})$. The energy content of 59 samples of milk was estimated from the measured concentrations of fat, protein, and lactose using the formula: (lactose $(\mathrm{g} / \mathrm{l}) \times 3.95)+$ (protein $(\mathrm{g} / \mathrm{l}) \times 4.0)+($ fat $\quad(\mathrm{g} / \mathrm{l}) \times 9.0)=\mathrm{kcal} / \mathrm{l}$. The accuracy of the method $(95 \%$ confidence limits) is $\pm 42 \mathrm{kcal} / \mathrm{l}$, which for average expressed milk is around $6 \%$.

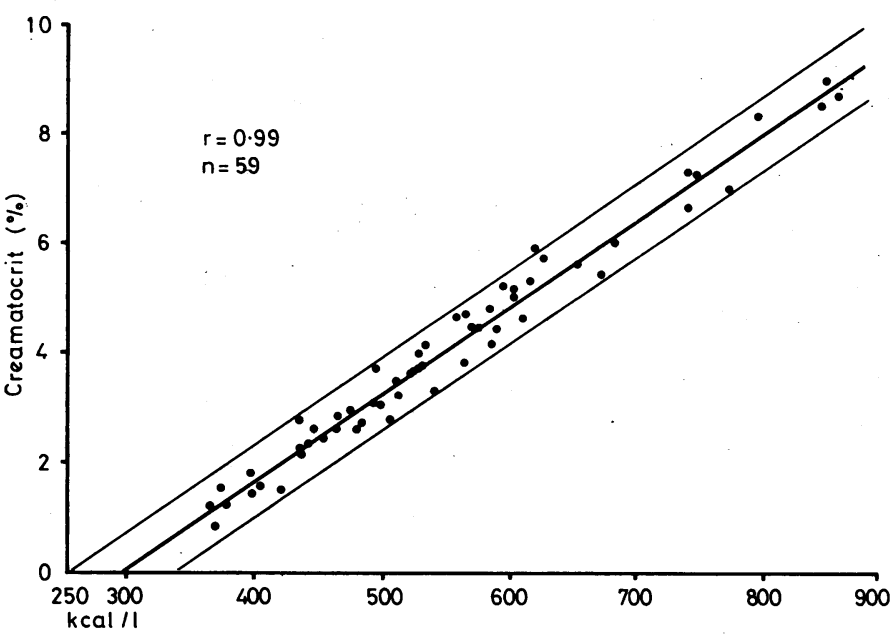

FIG 3-Relation between creamatocrit and energy value. Linear regression line with $95 \%$ confidence limits. $\mathrm{kcal}=(290+66 \cdot 8) \times$ creamatocrit. $(1000$ $\mathrm{kcal} \approx 4 \cdot 2 \mathrm{MJ}$.)

In addition 10 creamatocrit measurements were performed on each of three milk specimens with widely differing fat concentrations. The results (see table) indicated that consecutive measurements on the same specimen of average expressed milk would be expected to have a coefficient of variation of about $2 \%$.

Results of repeated creamatocrit estimations on three samples of human milk

\begin{tabular}{|c|c|c|c|c|}
\hline Sample & $\begin{array}{c}\text { No of } \\
\text { estimates }\end{array}$ & 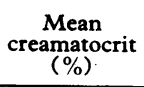 & $\begin{array}{l}\text { Standard } \\
\text { deviation }\end{array}$ & $\begin{array}{c}\text { Coefficient of } \\
\text { variation } \\
(\%)\end{array}$ \\
\hline $\begin{array}{l}\mathbf{A} \\
\mathbf{B} \\
\mathbf{C}\end{array}$ & $\begin{array}{l}10 \\
10 \\
10\end{array}$ & $\begin{array}{r}1.61 \\
5.68 \\
11.74\end{array}$ & $\begin{array}{l}0 \cdot 10 \\
0 \cdot 12 \\
0 \cdot 15\end{array}$ & $\begin{array}{l}6 \cdot 0 \\
2 \cdot 2 \\
1 \cdot 3\end{array}$ \\
\hline
\end{tabular}

\section{Discussion}

The percentage of cream in human milk correlates well with the fat concentration and energy content. Fat and energy values may be read from standard graphs (figs 2 and 3) or calculated arithmetically from the formulae: fat $(\mathrm{g} / \mathrm{l})=$ (creamatocrit $(\%)-0.59) / 0 \cdot 146 ; \quad \mathrm{kcal} / \mathrm{l}=(290+66 \cdot 8) \times$ creamatocrit $(\%)$. Average expressed milk contains about $40 \mathrm{~g}$ of fat $/ 1^{6}$ and 700 $\mathrm{kcal} / 1,6$ and at these levels the creamatocrit technique has an accuracy of around $\pm 10 \%$ and $\pm 6 \%$ respectively, which is quite adequate for most clinical and many research purposes. The method is particularly useful when only small samples are available for analysis: the Gerber technique, for example, requires 150 times the sample size. 
For calculating energy values from concentrations of fat, protein, and lactose in milk we used the energy conversion formula described by Southgate and Durnin. ${ }^{7}$ Several conversion formulae have been described: some are based on heats of combustion; others, which represent an attempt at estimating "availabie" energy, are based on metabolic studies. In infant nutrition available energy from a milk diet is likely to vary with postnatal age, gestational age, and illness: hence it is not always possible to select a suitable conversion formula on physiological grounds. The main purpose of a numerical value for milk energy is to compare milks of different quality. The formula of Southgate and Durnin is convenient since it is popular with nutritionists, and our derived energy values are therefore comparable with those in other studies.

The linear relation between the calculated energy value and the creamatocrit was due to the relative constancy of the energy contribution of protein and lactose in milk: this occurs partly because of the inverse relation between milk protein and lactose concentrations and partly because of the relatively stable concentration of lactose, which contributes much more to total milk energy than the relatively more variable protein concentration. Thus energy variation in milk is nearly all due to variation in fat and hence cream content.

Breakdown of the milk fat globule membrane might theoretically be expected to produce falsely low creamatocrit values, since free fat occupies less space than cream, which contains water. Two factors that might have affected stability of the milk fat globule membrane-namely, milk lipase and temperaturewere considered. Milk lipase is present in sufficient quantities to hydrolyse all the fat in milk and hence destroy the cream layer. ${ }^{*}$ Milk lipase, however, requires specific activation-for example, by bile ${ }^{8}$ - and is unlikely to be activated in untreated human milk, even if stored at room temperature. ${ }^{9}$ We have investigated the effects of freezing for up to two months (15 samples) and pasteurisation at $62.5^{\circ} \mathrm{C}$ for 30 minutes (eight samples) on the creamatocrit: neither changed the creamatocrit significantly or measurably changed the layer of free fat that is sometimes seen above the cream layer. Thus the creamatocritz technique may be used on batches of stored frozen samples.

The creamatocrit technique is a simple, inexpensive, and rapide micromethod for estimating the fat concentration and energy content of human milk. It may be used in clinical, research, and? epidemiological investigations.

We thank Mrs P Goddard (National Institute for Research in Dairying) for performing lactose and protein assays, and Miss $M_{\Omega}^{\mathbb{\Phi}}$ Butler (NIRD) for help with the fat assays. AL is in receipt of an Wellcome Trust research fellowship. JAHG was supported by the ${ }^{\text {s }}$ Canadian Medical Research Council.

\section{References}

${ }^{1}$ Fleet, I R, and Linzell, J L, fournal of Physiology, 1964, 175, 15. British Standards Institution, Gerber method for determination of fat in milk and milk products, 1955, BS696.

${ }^{3}$ Bosset, J, Blanc, B, and Plattner, E, Analytica Chimica Acta, 1974, 70, 327.

${ }^{4}$ Bosset, J, Blanc, B, and Plattner, E, Analytica Chimica Acta, 1974, 71, 97.0

${ }^{5}$ Marier, J R, and Boulet, M, Fournal of Dairy Science, 1959, 42, $1390 . \quad \vec{\infty}$ DHSS, Report on Health and Social Subjects 12: Composition of Mature $\mathrm{O}$
Human Milk. London, HMSO, 1977 .

'Southgate, D A T, and Durnin, J V G A, British fournal of Nutrition, N $1970,24,517$.

${ }^{8}$ Hall, B, Biochemical Society Transactions, 1975, 3, 90.

${ }^{9}$ Hall, B, personal communication.

(Accepted 16 February 1978)

\title{
After-exercise thermography for predicting postoperative deep vein thrombosis
}

\author{
H P HENDERSON, E D COOKE, SALLY A BOWCOCK, M E J HACKETT
}

British Medical fournal, 1978, 1, 1020-1022

\section{Summary and conclusions}

After-exercise thermography of the legs was carried out on 50 patients before undergoing major abdominal surgery (group 1) and on 59 patients before elective hip surgery (group 2). The incidence of postoperative deep vein thrombosis (DVT)-diagnosed by the ${ }^{125}$ I-fibrinogen uptake test in group 1 and phlebography in group 2-was significantly higher in patients whose after-exercise thermogram (AET) had been abnormal. Out of 19 patients in group 1 and 30 in group 2 with a normal AET, two and nine respectively developed postoperative DVT. Among patients with a unilaterally abnormal AET the

The London Hospital, London E1 2AD

H P HENDERSON, MB, FRCS, registrar in plastic surgery

$M$ E J HACKETT, MB, FRCs, consultant plastic surgeon

Department of Medical Electronics, St Bartholomew's Hospital, London EC1A 7BE

E D COOKE, MD, research consultant, clinical thermographic unit SALLY A BOWCOCK, SRN, SCM, research assistant incidences were 12 out of 19 patients in group 1 and five out of nine in group 2. The incidences among patients with a bilaterally abnormal AET rose to 11 out of 12 응 patients in group 1 and 15 out of 20 in group 2.

Preoperative after-exercise thermography is a simple, $\stackrel{\sim}{\circ}$ objective test that identifies patients at high risk of developing postoperative thromboembolic disease.

\section{Introduction}

The grey-tone thermogram of the anterior aspect of the raised calf is characteristically cool, with no hot areas (hot spots). The skin overlying the patella and subcutaneous border of the tibia are the coolest areas and the skin overlying the calf muscles the warmest (see fig $(a)$ ). This pattern is accentuated in a normal leg after three minutes of walking on the spot (fig $(b)$ ). In contrast, $\frac{\mathcal{Q}}{\mathbb{Q}}$ the after-exercise thermogram (AET) of a leg with phlebographically confirmed chronic venous insufficiency shows $a$ network of linear hot spots crossing the anterior tibia (fig $(c)) .{ }^{1} 0$

Deep venous incompetence or deep venous damage may predispose a patient to postoperative deep vein thrombosiso(DVT). As part of a larger study on the thermographic detection? of DVT we examined the incidence of postoperative DVT in patients undergoing elective abdominal and hip surgery who had normal and abnormal preoperative AETs. 